\title{
An Integrated Approach for the Identification of HNF4 $\alpha$-Centered Transcriptional Regulatory Networks During Early Liver Regeneration
}

\author{
Heng Jiao a,b Yuping Zhuc Shan Lu ${ }^{d}$ Yongxia Zheng ${ }^{\mathrm{e}}$ Huan Chen ${ }^{\mathrm{b}}$ \\ aDepartment of General Surgery, Zhongshan Hospital, Shanghai Medical College of Fudan \\ University,Shanghai, 'State Key Laboratory of Proteomics, Beijing Proteome Research Center, Beijing \\ Institute of Radiation Medicine, Beijing, 'Basic Medical Experimental Teaching Center, Second Military \\ Medical University, Shanghai, 'Department of Biochemistry and Molecular Biology, Second Military \\ Medical University, Shanghai, eMedical College, Jiaxing University, Jiaxing, China
}

\section{Key Words}

Liver regeneration - Transcriptional regulatory network - Microarray - Hepatocyte nuclear factor- $4 \alpha$

\begin{abstract}
Background/Aims: Hepatocyte nuclear factor- $4 \alpha$ (HNF4 $\alpha$ ), the liver enriched transcription factor (TF), is one of the major regulators of hepatocyte differentiation and proliferation. However, how HNF4 $\alpha$ participate in liver regeneration after partial hepatectomy $(\mathrm{PH})$ remains largely unknown. In order to identify the $H N F 4 \alpha$-centered regulatory network, we applied an integrated analytic strategy, in which, TF array, mRNA microarray, bioinformatic analysis and ChIP-on-chip assays were integrated. Methods/Results: The TF signatures from MOUSE OATFA (TF-array) platform revealed that the activity of HNF4 $\alpha$ was significantly reduced and 17 other TFs showed increased activity at $4 \mathrm{~h}$ post PH. Then the ChIP-on-chip analysis on HNF4 $\alpha$ were combined with mRNA expression profiling to select the possible HNF4 $\alpha$ target genes during early liver regeneration, which were then sub-grouped according to their signaling pathways. More specifically, the HNF4 $\alpha$ target genes with the gene ontology (GO) terms of cytokine-cytokine receptor, Jak-STAT, MAPK, toll-like receptor and insulin signaling pathways were further analyzed with an advanced bioinformatics tool named oPOSSUM to identify TF binding sites occupancy and predict the co-regulatory relationship between TFs and targets. Furthermore, we identified that repressed HNF4 $\alpha$ during the early phase of liver regeneration may contribute cooperatively to the induction of immediate early genes, such as, $c$-fos, c-jun and stat3. Conclusion: our data indicate that HNF4 $\alpha$ may play an inhibitory role on the induction of specific promitogenic genes and liver regeneration initiation. The integrated approach of mRNA/OATFA/ChIP-DSL/oPOSSUM analysis may help us better characterize the target genes and co-regulatory network of HNF4 $\alpha$ during the early stage of liver regeneration.

Copyright (C) 2015 S. Karger AG, Basel

H. Jiao and Y. Zhu contributed equally.

Huan Chen

and Yongxia Zheng

State Key Laboratory of Proteomics, Beijing Proteome Research Center, Beijing Institute of Radiation Medicine, \#33 Life Science Park Road, Beijing 102206, (China) and Medical College, Jiaxing University, \#118 Jiahang Road, Jiaxing 314001, ZJ (China) E-Mail chenhuan@smmu.edu.cn, E-Mail zhengyongxia@163.com
\end{abstract}

KARGER 125 


\section{Cellular Physiology Cell Physiol Biochem 2015;36:2317-2326 \begin{tabular}{ll|l} 
and Biochemistry $\begin{array}{l}\text { DOI.1159/000430195 } \\
\text { Published online: July 27, } 2015\end{array}$ & $\begin{array}{l}\text { O 2015 S. Karger AG, Basel } \\
\text { www.karger.com/cpb }\end{array}$ \\
\cline { 2 - 3 }
\end{tabular} \\ Jiao/Zhu/Lu/Zheng/Chen: HNF4a-Centered Transcriptional Network During Liver Regeneration}

\section{Introduction}

Despite liver has a tremendous potential of regeneration in response to external stimuli $[1,2]$, some patients who undergo hepatectomy still experience postoperative liver failure due to insufficient regeneration. Hence, the liver regeneration process is of great importance in maintaining liver health. Defining the underlying mechanism of the process holds promise to augment liver regeneration and design treatment for liver diseases [1-3].

In recent years, there have been major advances in exploring of the mechanisms of liver regeneration. It is currently known that in response to tissue injury, cytokines and chemokines are stimulated, which result in activation of some downstream transcription factors (TFs), including nuclear factor- $\kappa \mathrm{B}(\mathrm{NF}-\kappa \mathrm{B})$, activator protein 1 (AP-1), signal transducers and transcription activators 3 (STAT3) and CCAAT enhancer-binding protein (C/EBP), and then a large number of genes (including promitogenic genes and homeostatic response genes) were induced so as to initiate regeneration. However, the mechanisms of liver regeneration in priming phases are still largely unexplored.

Hepatocyte nuclear factor- $4 \alpha$ (HNF4 $\alpha$ ), a liver-enriched TF and the major regulator of hepatocyte differentiation, and has been recently shown to inhibit hepatocyte proliferation within liver [2,4]. Coincidentally, our previous study using an advanced mouse oligonucleotide array-based transcription factor assay (MOUSE OATFA) platform for TF activity profiling, have suggested that the activity of HNF $4 \alpha$ was repressed in regenerating mouse liver tissues $4 \mathrm{~h}$ after partial hepatectomy ( $\mathrm{PH})$, compared to the sham operation ( $\mathrm{SH}$ ) group. Till now, however, how HNF4 $\alpha$ is involved in the priming stage of liver regeneration remains largely unknown. Through classical promoter analysis and recent genome-wide location analysis, functional HNF4 $\alpha$-binding sites have been identified in multiple classes of genes, including those involved in metabolism of lipids, glucose, and amino acids, as well as apoptosis, signal transduction, stress response and cancer related [5-8]. In is well-recognized that liver regeneration is a highly synchronized process precisely controlled by a large group of genes in various pathways. Therefore, based on the above evidence, we speculated that HNF4 $\alpha$ may play an essential role in the transcriptional reprogramming of hepatocytes during the early phase of liver regeneration, via transcriptional activation or suppression.

In the present study, we aimed to investigate the potential target genes of HNF $4 \alpha$ and co-regulatory networks between TFs that are active in the liver tissues of adult mice. Briefly, TF activity profiling, mRNA microarray, chromatin immunoprecipitation followed by microarray analysis (ChIP-on-chip), as well as bioinformatic analysis were integrated. And the microwell colorimetric TF-ELISA assays were conducted to verify the changes of TF activity. Based on the above strategies, we identified a specific co-regulatory network governed by HNF $4 \alpha$ in the priming stage of liver regeneration.

\section{Materials and Methods}

\section{Ethics Statement}

All animals were cared appropriately according to the Institutional Animal Care Instructions approved by the Ethics Committee for Animals of the Second Military Medical University. All experiments were performed in accordance with the Institutional Animal Care Instructions approved by the Ethics Committee for Animals of the Second Military Medical University (Approval ID: SCXK 2007-0003).

Animals and Surgery

8-10 week-old male C57BL/6 mice were randomly assigned to $\mathrm{PH}$ and SH groups (3 6 animals in each group) and fed standard laboratory chow ad libitum with free access to water. After an overnight fast, mice were injected with sodium pentobarbital (30 mg/kg, intraperitoneally), and underwent 70\% $\mathrm{PH}$ or sham according to the method of Higgins and Anderson. For sham operation (SH), mice underwent laparotomy under anaesthesia without tissue removal. Mice were offered food and water ad libitum after the operation. 
At $4 \mathrm{~h}$ after surgery, the animals were euthanized, and the remaining liver tissues were collected for subsequent examination.

\section{The MOUSE OATFA assay}

Nuclear proteins were extracted from three PH (4h) and three SH controls using the NE-PER Nuclear and Cytoplasmic Extraction Reagents (Pierce, Rockford, IL, USA). BCA Protein Assay Kit (Pierce) was used to determine the nuclear protein concentrations. The MOUSE OATFA (TF-array) system (CapitalBio, Beijing, China) was performed as described [9]. Three independent experiments were performed in $\mathrm{PH}$ or $\mathrm{SH}$ groups. Differentially DNA-binding activity of a TF were screened using the 2-sample t-test $(\mathrm{p}<0.05)$ and the median ratio was $\geq 1.5$.

\section{Microwell colorimetric TF-ELISA assays}

The TF-array data were verified by Microwell colorimetric TF-ELISA assays in six PH liver samples and six SH controls, by using antibodies against C/EBP- $\alpha$, AP1, NF- $\kappa B, N F 1$, and HNF4 $\alpha$ (Santa Cruz, CA, USA). The binding sequences for the transcription factors were listed as follows: AP1 5'-CTC GAC CCG AAT GAG TCA GCA TGA GTA GTG-3'; C/EBP 5'-AAT ATT GCC CAA CCA ACA TTG CGT AAG GAC-3'; NF-кB 5'-GGA GGG ACT TTC CAA GAG GGA CTT TCC AAG-3'; USF1 5'-TAC GAG CCA CGT GAC ATG TCA CGT GAC ATG-3'; HNF4 5'-AGC GTA CAG GGT CAA AGG TCA AGG CTC AAG-3'. Since the TF-target gene interaction predicted by ChIP-DSL and oPOSSUM analysis was based on the proximal promoter region $(-800 \mathrm{bp}$ to +200 bp) relative to the transcription start sites (TSS), PCR primers were designed according the above region for each validated genes in Fig. 5B. The biotin-labeled PCR products were recovered and connected to the streptavidin-coated 96-well plates. Then the TF-ELISA assays were conducted by using C/EBP- $\alpha, \mathrm{NF}-\kappa \mathrm{B}$, upstream stimulatory transcription factor 1 (USF1), and HNF4 $\alpha$ antibodies. The PCR primers used for probe in microwell colorimetric TF-ELISA Assays: Fos forward 5'- CTA CAC GCG GAA GGT CTA GG -3', Fos reverse 5'- GTC GCG GTT GGA GTA GTA GG -3'; Jun forward 5'- GAG CAT TAC CTC ATC CCG TG -3', Jun reverse 5'- CCG TCT GTC TGT CTG TCT GC -3'; Stat3 forward 5'- AGC CTT GCT GTT GAG ATT C -3', Stat3 reverse 5'- GCA TTT GGG TTT GTG GAG -3'.

\section{mRNA expression profiling and data analysis}

The mouse genome $35 \mathrm{~K}$ oligonucleotide microarray was constructed at CapitalBio Corporation (Beijing, China). Total RNA was isolated from either prepared liver samples or transfected cells by the Trizol (Invitrogen, Carlsbad, CA, USA) reagent. The fluorescent dye-labeled cDNA was produced using Eberwine's linear RNA amplification method and was purified using PCR Clean-up NucleoSpin kits (Macherey Nagel, Duren, Germany). Hybridization was performed under LifterSlip ${ }^{\mathrm{TM}}$ (Erie, Portsmouth, NH, USA). Fluorescent images of hybridized microarrays were obtained using a confocal LuxScan ${ }^{\mathrm{TM}} 10 \mathrm{~K}-\mathrm{A}$ scanner (CapitalBio) and followed by analysed with LuxScan 3.0 Software (CapitalBio). The differentially expressed mRNAs, defined as those with either $\leq 0.5$ - or $\geq 2$-fold changes and $P<0.05$, were selected using the program Significance Analysis of Microarrays (SAM, http://www-stat. stanford.edu/ tibs/SAM/). Differentially expressed genes were mapped using the integrated Molecular Annotation System (MAS, http://bioinfo. capitalbio.com/mas).

\section{Transcription factor binding sites}

Over-representation analysis were performed to determine the enrichment of TFBS using the oPOSSUM software (http://burgundy.cmmt.ubc.ca/oPOSSUM/) and the mouse TFBS matrices were obtained from the JASPAR database.

ChIP-DSL

ChIP-DSL system were used to assess the potential promoter occupancy by HNF4 $\alpha$ in liver regeneration. PH or SH liver tissues at $4 \mathrm{~h}$ post surgery were homogenized and underwent ChIP with DNA selection and ligation (ChIP-DSL). After ChIP, HNF4 $\alpha$-associated DNA were amplified, labeled using a Biotin Labeling Kit (Vector Laboratories, Burlingame, CA, USA), and hybridized using the Aviva's Hu20K arrays. Slides were scanned on the LuxScan ${ }^{\mathrm{TM}} 10 \mathrm{~K}-\mathrm{A}$ (CapitalBio). The target gene was deemed to be regulated significantly if the enriched ratio was $\geq 2$ and the $P$ value was $\leq 0.05$. 


\section{Cellular Physiology Cell Physiol Biochem 2015;36:2317-2326 \begin{tabular}{l|l|l} 
DOI: 10.1159/000430195 & O 2015 S. Karger AG, Basel \\
www.karger.com/cpb
\end{tabular}

\section{Results}

\section{TF activity profiling using MOUSE OATFA platform}

In order to profile the activity changes in TFs during early liver regeneration, a MOUSE OATFA platform which includes 240 specific probes targeting 200 TFs simultaneously was applied. As shown in Table 1 and Fig. 1A, we identified that the activity of 18 TFs were significantly changes with $>1.5$-fold or $<0.67$-fold. Among them, some have been previously reported in a number of studies, including C/EBP, AP-1 and NF1 and USF1 [10-17]. However, as one of the most essential TFs, the activity changes of HNF4 $\alpha$ in regenerating livers has not been reported. Our data suggests that during the priming phase of liver regeneration, the activity of HNF4 $\alpha$ was significantly downregulated. To confirm our data, we also conducted an antibody-based TF-ELISA colorimetric assay on several TFs (Fig. 1B). TFs such as AP1, NF-1, NF- $\mathrm{KB}$ and C/EBP are known to be upregulated shortly after PH, and their activity changes have been confirmed by TF-ELISA assay. More importantly, the activity of HNF4 $\alpha$ was significantly downregulated, as revealed by TF-ELISA assay, which agreed with the data analyzed by the OATFA estimations of $H N F 4 \alpha$.

\section{mRNA expression profiling using microarray analysis}

We also conducted the mRNA expression profiling on regenerating liver tissues at 4 h post surgery. As shown in Fig. 2A, we identified over 700 differentially expressed mRNA ( $\geq 2$-fold or $\leq 0.5$-fold) in PH liver tissues, as compared to the SH groups ( $p<0.05, n=3$ ). Then these differentially expressed genes were subjected to pathway analysis via an online MAS 3.0 platform (http://bioinfo.capitalbio.com/mas). As shown in Fig. 2B, 5 signaling pathways with the largest number of genes are listed, including the cytokine-cytokine receptor, JakSTAT, MAPK, Toll-like receptor and insulin signaling pathways. Genes involved in the Top 5 pathways have been extensively studied in previous reports.

\section{Identification of HNF4 $\alpha$ target genes}

Integration of ChIP-on-chip analysis and gene expression profiling has been reported to be an effective strategy to identify potential target genes of a specific $\mathrm{TF}$ and its co-regulator [16]. Firstly, we employed a ChIP-DSL analysis to identify potential target genes of HNF $4 \alpha$, which is a new ChIP-onchip model that offers a powerful strategy to evaluate in vivo binding profiles of a specific TF with high accuracy [17]. In the ChIP-DSL Hu20K arrays, the probes were designed corresponding to a proximal promoter region $(-800 \mathrm{bp}$ to $+200 \mathrm{bp})$ relative to the TSS. Here we identified that 3544 gene exhibited significant enrichment in HNF4 $\alpha$ binding in the regenerating livers (in the $\mathrm{PH}$ group), as compared with IgG control (Fig. $3 \mathrm{~A}$, left circle).

Secondly, the 3544 potential target genes of HNF $4 \alpha$ was further overlapped with the differentially expressed genes obtained via mRNA profiling during early liver regeneration, so as to select the most possible target regulated by HNF $4 \alpha$. The overlapping area of the Venn diagram revealed that 126 of 774 differentially expressed genes are
Table 1. TF activity analysis using TF-array during liver regeneration. $*$ The median ratio value of $\geq 1.5$ or $\leq 0.67$ was listed

\begin{tabular}{|c|c|c|c|c|}
\hline $\mathrm{TF}$ & PH1/SH1 & $\mathrm{PH} 2 / \mathrm{SH} 2$ & PH3/SH3 & average ratio* \\
\hline HNF4 $\alpha$ & 0.67 & 0.47 & 0.66 & 0.60 \\
\hline FOXC1 & 1.43 & 1.50 & 1.81 & 1.58 \\
\hline NKX6-1 & 1.51 & 1.42 & 1.84 & 1.59 \\
\hline FOXL1 & 1.91 & 1.95 & 1.33 & 1.73 \\
\hline AP1 & 1.88 & 1.93 & 1.48 & 1.76 \\
\hline SRY & 1.76 & 1.57 & 1.97 & 1.77 \\
\hline ATF family & 1.84 & 1.81 & 1.73 & 1.79 \\
\hline CUTL1 & 2.19 & 1.57 & 1.69 & 1.82 \\
\hline HNF1 & 1.93 & 1.86 & 2.22 & 2.00 \\
\hline RFX1 & 1.97 & 2.08 & 2.16 & 2.07 \\
\hline ATF/AP1 & 2.38 & 2.03 & 1.83 & 2.08 \\
\hline OC2/HNF6 & 2.35 & 2.20 & 2.01 & 2.18 \\
\hline FOXD1 & 2.30 & 2.39 & 2.15 & 2.28 \\
\hline E4BP4 & 2.33 & 1.98 & 2.56 & 2.29 \\
\hline NFE2 & 2.26 & 2.11 & 3.32 & 2.56 \\
\hline $\mathrm{C} / \mathrm{EBP}$ & 3.10 & 3.13 & 2.86 & 3.03 \\
\hline NF-1/CTF & 4.10 & 3.45 & 2.98 & 3.51 \\
\hline ATF2/HLF & 4.11 & 4.42 & 3.33 & 3.95 \\
\hline
\end{tabular}




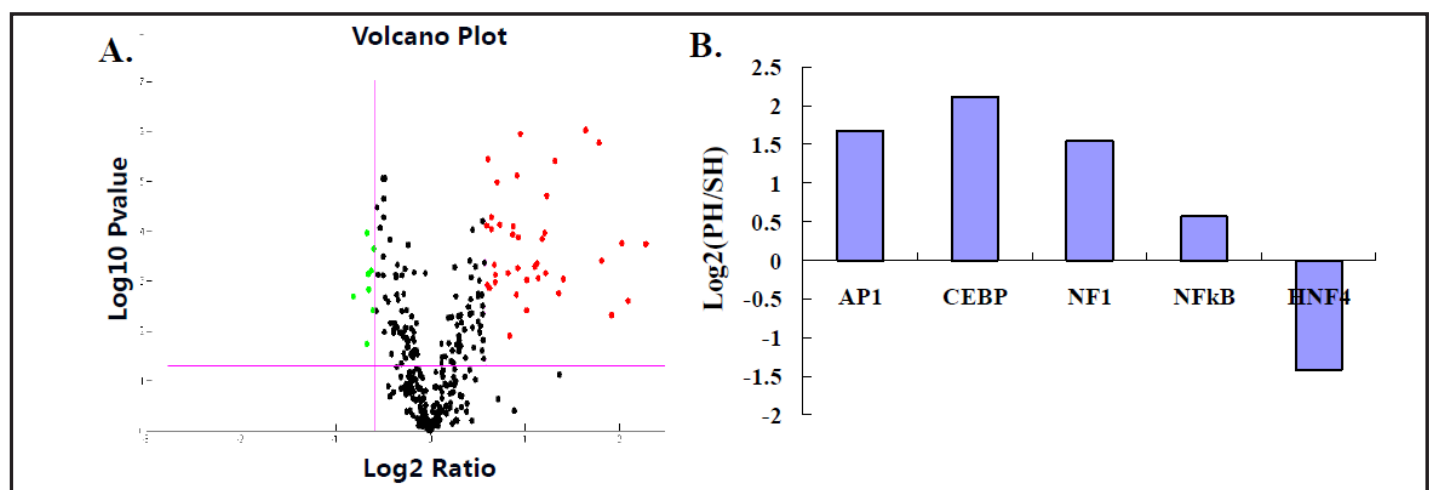

Fig. 1. TF activity analysis using the MOUSE OATFA and TF-ELISA platform. A. Volcano plots of MOUSE OATFA (TF array) analysis. The activities of TFs were analyzed in three PH and three SH mouse liver tissues (4 h-post surgery). TFs with $>1.5$-fold or $<0.67$-fold change were deemed significantly changes. Red: TFs with upregulated activity; green: TFs with downregulated activity. B. TF activities in PH and SH liver tissues were monitored using an antibody-based TF-ELISA colorimetric assay (six samples in each group). The data of each TF is shown as the ratio of the colorimetric readout in PH tissue to that of SH tissues.

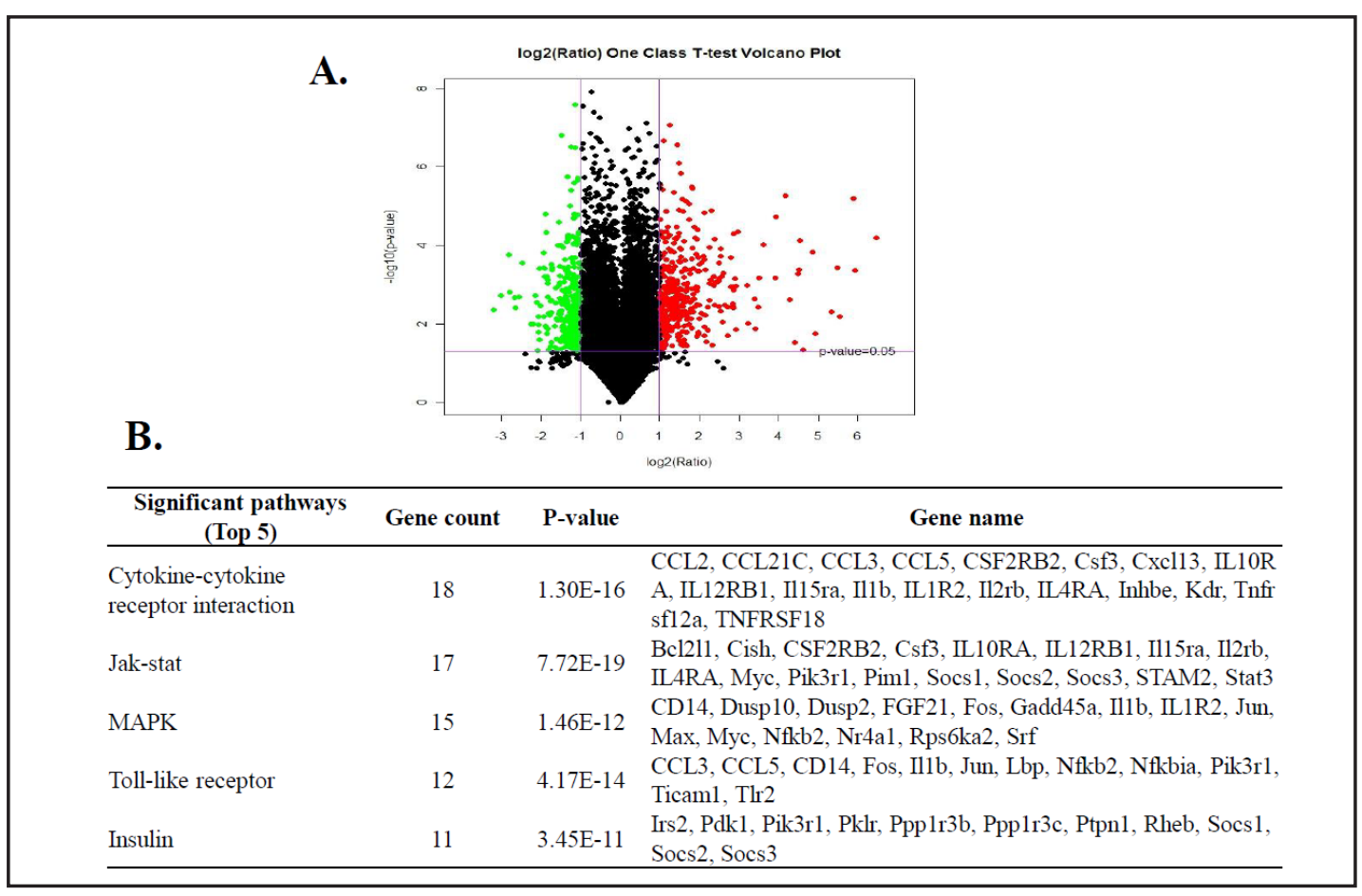

Fig. 2. Differentially expressed genes during early liver regeneration using mRNA microarray. A. Volcano plots of mRNA profiling in three regenerating mouse liver tissues (4 h-post PH) and three SH control tissues. B. The most significant GO terms (Top5) enriched in the regenerating liver tissues.

possibly regulated by HNF4 $\alpha$ (Fig. 3A), indicating that HNF4 $\alpha$ may play an essential role in liver regeneration priming.

Thirdly, to answer how HNF4 $\alpha$ is involved in liver regeneration, we then subjected the 126 possible target genes of HNF4 $\alpha$ to pathway analysis (Fig. 3B), which reveals that 15 of them belong to the top 5 signaling pathways as summarized in Fig. 2B. There are five genes enriched in Jak-stat signaling (Bcl2l1, Cish, Pim1, Socs2, Stat3), four in MAPK (Fos, Il1b, Jun, Max, Srf), four in insulin pathways (Pklr, Ptpn1, Rheb, Socs2), three in cytokinecytokine receptor interaction (Il1b, Inhbe, Tnfrsf12a) and three in toll-like receptor signaling pathways (Fos, Il1b, Jun). 
B.

\section{A. HNF4 regulated genes Differentially expressed genes}

\begin{tabular}{ll}
\hline Significant pathways (Top 5) & Potential HNF4A target gene \\
\hline Cytokine-cytokine receptor interaction & Illb, Inhbe, Tnfrsf12a \\
Jak-stat & Bcl211, Cish, Pim1, Socs2, Stat3 \\
MAPK & Fos, Il1b, Jun, Max, Srf \\
Toll-like receptor & Fos, Illb, Jun \\
Insulin & Pklr, Ptpnl, Rheb, Socs2 \\
\hline
\end{tabular}

Fig. 3. Genome-wide identification of HNF4 $\alpha$ target genes during the early phase of liver regeneration. A. Venn Diagram indicates the overlap of genes identified in ChIP-DSL experiments (3544 HNF4 $\alpha$ potential target genes) and mRNA expression profiling (774 differentially expressed genes in regenerating livers). B. Pathway analysis of HNF4 $\alpha$ target genes. Candidate HNF $4 \alpha$ target genes belong to the Top 5 pathways (described in Fig. 2B) were identified.

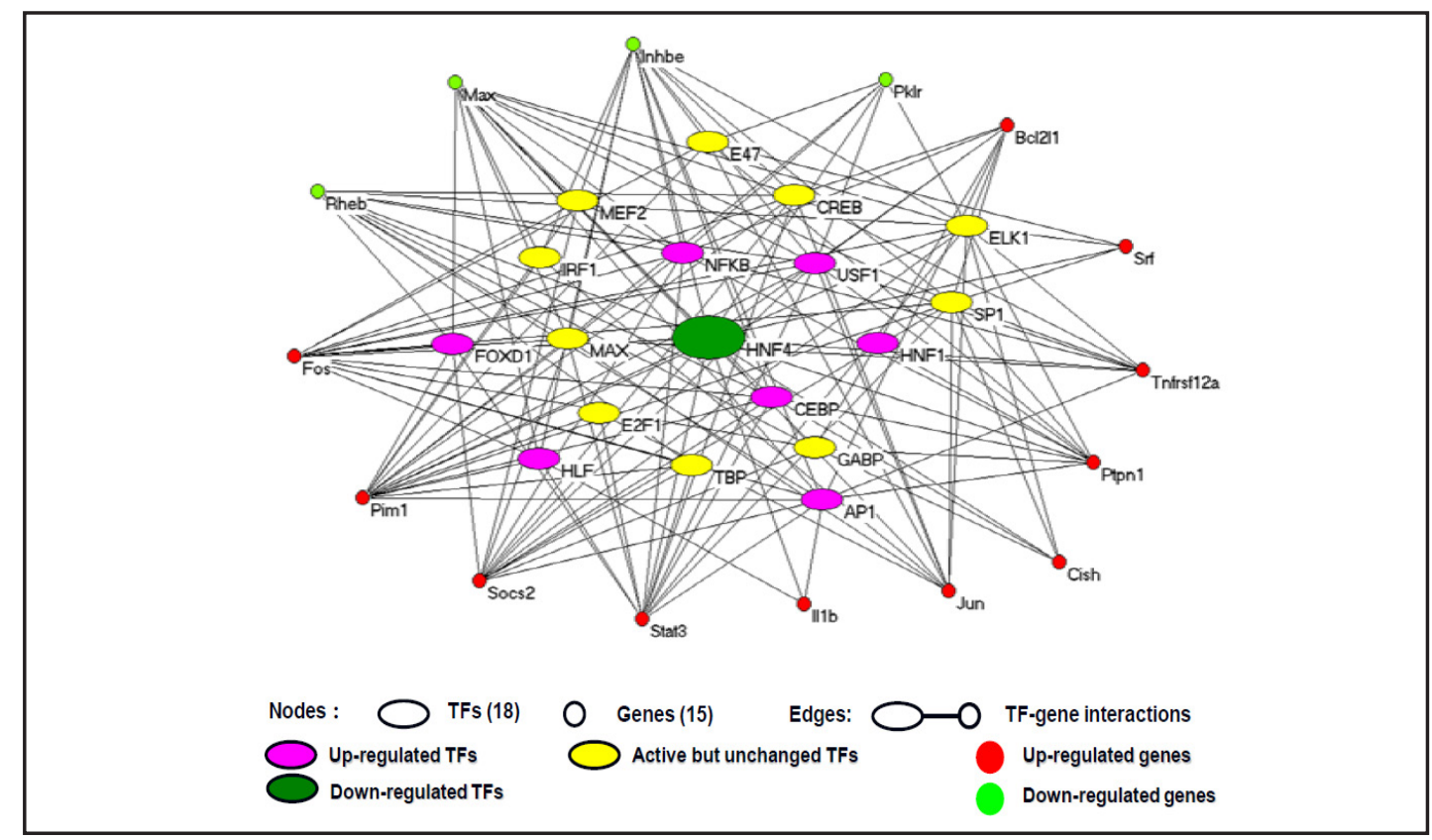

Fig. 4. HNF4 $\alpha$-centered regulatory networks in the early phase of liver regeneration in mice. Kamada-Kawai interaction network of HNF4A, 15 of its predicted target genes (from the Top 5 important signaling pathways) and 17 coregulatory TFs, as predicted by oPOSSUM analysis. The dot symbols represent target genes, and the oval symbols represent coregulatory TFs. The lines linking a specific target gene and its TFs indicate coregulatory relationships.

HNF4 $\alpha$-centered regulatory networks during early liver regeneration

To display the co-regulatory network of between HNF4 $\alpha$ and other TFs in regulating the 15 important genes shown in Fig. 3B, we applied an advanced bioinformatics tool named 
Fig. 5. TF-ELISA validation of the coregulatory relationships in mouse regenerating liver tissue. A. Four genes among the 15 possible HNF4 $\alpha$ target genes (Fig. 3B) were randomly selected and the coregulatory relationships among four TFs were shown, as predicted by oPOSSUM analysis. B. The coregulatory relationships predicted in Fig. 5A was further validated by TF-ELISA assay. Red +: regulatory relationship; green -: no regulatory relationship.

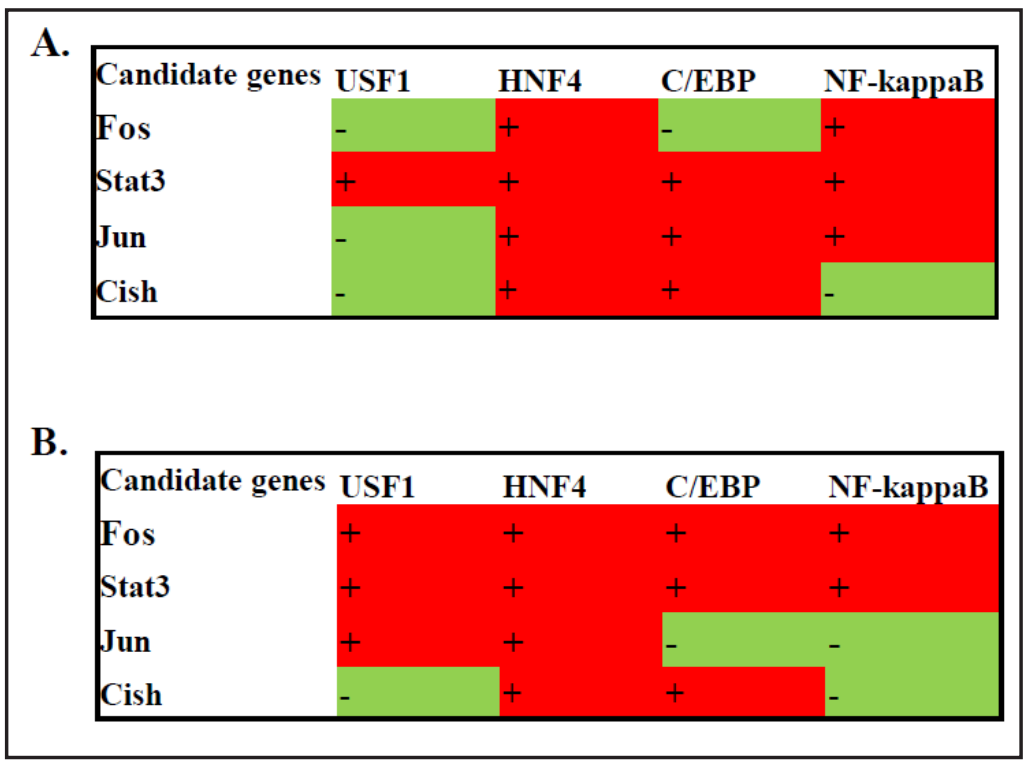

oPOSSUM to identify TF binding sites occupancy and predict the co-regulatory relationship between TFs and targets. We have previously reported that $43 \mathrm{TFs}$ were found to be active in normal liver tissues in mice via the OATFA (TF-array) platform [16], among which the binding matrix of 18 TFs were included in the present analysis. The selection of 18 TFs including HNF4 suggests that these active TFs in regenerating liver tissues (1 downregulated TF, 6 upregulated TFs and 10 active but unchanged TFs) might be involved in the transcriptional regulation of the 15 target genes. In the constructed regulatory network in Fig. 4, the interactions between TFs (oval symbols) and their potential target genes (dot symbols) are represented by the edge lines linking the two kinds of symbols.

To validate the predicted coregulatory network between the 15 genes and 18 TFs, we randomly selected the interactions between 4 target genes and 4 TFs (including HNF4 $\alpha$ ) for experimental evaluation by using TF-ELISA analysis. As revealed in Fig. 5, 11 interactions were predicted by the oPOSSUM/ChIP-DSL/OATFA strategy (Fig. 5A), and 9 of them were confirmed by TF-ELISA assays. Therefore, the integrated approach has offered us with a simplified strategy to identify unknown interactions between TFs and their target genes. For instance, $c$-fos, $c$-jun and stat 3 are well-known for their essential roles in promoting liver regeneration, and our investigation suggested that these genes are co-regulated by a subset of TFs. Since the activity of HNF $4 \alpha$ was repressed during the early phase, it is convincible that $\mathrm{HNF} 4 \alpha$ may play a transcriptional repressive role.

\section{Discussion}

We have adopted the integrated approach of mRNA/OATFA/ChIP-DSL/oPOSSUM analysis to characterize the target genes and co-regulatory network of USF1 during early liver regeneration in our previous study [16]. To the best of our knowledge, it was the first report of TF activity profiling during liver regeneration. In our investigation, we also uncovered that the activity of HNF4 $\alpha$, the most abundant transcription factor in the liver, was downregulated shortly after PH. To clarify how HNF4 $\alpha$ participate in the transcriptional control in regenerating livers, we employed two strategies. First, the potential target gene of HNF4 $\alpha$ was determined by combining the ChIP-on-chip and mRNA microarray analysis. The gene ontology analysis was then carried out to define its biological relevance which indicated that HNF4 $\alpha$ is involved in MAPK, Jak-stat and insulin signaling pathways. Second, possible HNF4 $\alpha$ target genes dysregulated during liver regeneration was then analyzed with the oPOSSUM tool, so as to construct the co-regulatory network of HNF4 $\alpha$. 


\section{Cellular Physiology Cell Physiol Biochem 2015;36:2317-2326 \begin{tabular}{ll|l} 
and Biochemistry 10.1159/000430195 & $\begin{array}{l}\text { D 2015 S. Karger AG, Basel } \\
\text { Published online: July 27, } 2015\end{array}$ \\
\cline { 2 - 3 } & www.karger.com/cpb
\end{tabular} \\ Jiao/Zhu/Lu/Zheng/Chen: HNF4a-Centered Transcriptional Network During Liver Regeneration}

Table 2. TF activity analysis and potential regulatory role of HNF4 $\alpha$ on the target genes during liver regeneration

\begin{tabular}{lccc}
\hline Gene symbol & $\begin{array}{c}\text { PH/SH ratio } \\
\text { in mRNA expression }\end{array}$ & $\begin{array}{c}\text { PH/SH ratio } \\
\text { in ChIP-DSL }\end{array}$ & Potential role \\
\hline Pim & 4.63 & 0.28 & Repressive \\
Tnfrsf12a & 3.66 & 0.29 & Repressive \\
Fos & 5.75 & 0.24 & Repressive \\
Stat3 & 2.10 & 2.03 & Active \\
Jun & 3.88 & 2.85 & Active \\
\hline
\end{tabular}

In another aspect, we used another strategy to analyze the change of HNF4 $\alpha$ target gene between PH and sham samples. Particularly, we analyzed genes that have differentially binding in PH v.s. SH tissue samples by using ChIP-on-chip assays (Table 2), and then we compared them with the differentially expressed gene list from our microarray analysis. As a result, we identified 3324 genes with differential binding between PH and SH groups, including 111 differentially expressed genes after PH. More importantly, 17 genes (including jun, fos, and Myc and so on) are in the Top 5 signaling pathways (detail information upon request). We further identified 5 genes among 17 genes by oPOSSUM, which means that the upstream promoter regions of the 5 genes contain HNF $4 \alpha$ binding sites and they also show differential binding between PH and SH groups (Table 2). In other words, HNF4 $\alpha$ redistributes on genome during liver regeneration. Since HNF $4 \alpha$ usually act as a co-factor in transcriptional regulation, identifying the co-regulatory relationships among different transcription factors would be helpful in uncovering the regulatory role of HNF4 $\alpha$.

Our data revealed some interesting findings and may re-strengthen the role of $H N F 4 \alpha$ in initiating liver regeneration. It has been reported that specific TFs, such as, C/EBP, AP-1, STAT3, EGF and NF- $\mathrm{KB}$ are rapidly activated in the remnant liver tissues shortly after PH $[10,11,18-23]$. These events were followed by the first phase of gene expression alteration, including the upregulation of a group of promitogenic proto-oncogenes (e.g. $c$-fos, $c$-jun and $c-m y c$ ) , referred to as the immediate early genes [24-26]. Reduction in the activation of these factors may lead to liver regeneration abnormalities. However, there has been no report regarding the activity repression of $\mathrm{HNF} 4 \alpha$ after $\mathrm{PH}$ and its regulatory role in mediating the expression of c-jun or c-fos. As revealed in Fig. 4 and 5, $c$-jun or $c$-fos were predicted to be coregulated by multiple TFs including $\mathrm{HNF} 4 \alpha, \mathrm{C} / \mathrm{EBP}$, ELK1 and NF- $\kappa \mathrm{B}$, by using our integrated approach. This was in accordance with some previous studies. The promoter region of $c$-fos contains a serum response element (SRE), which is a convergence point for several signaling pathways that mediate induction of the $c$-fos gene. TFs such as serum response factor (SRF), ELK1, NF- $\kappa B$ and C/EBP are known to be the upstream regulators of $c$-fos $[27,28]$. Moreover, $\mathrm{C} / \mathrm{EBP} \alpha$ could interact with $c$-Jun through the leucine zipper domains, prevent it from binding to $c$-Jun DNA, and downregulate the expression of $c$-jun $[29,30]$. Here, we uncovered that the HNF $4 \alpha$ was also involved in the regulation of $c$-jun and $c$-fos, together with several other TFs (Fig. 4 and 5).

Recently, Chad et al. investigated the role of HNF4 $\alpha$ in the regulation of hepatocyte proliferation in a hepatocyte-specific deletion model. Their investigation showed that HNF4 $\alpha$ knockout resulted in increased hepatocyte proliferation and downregulated genes involved in hepatic differentiation. Conversely, overexpression of HNF4 $\alpha$ resulted in a decrease in promitogenic gene expression in hepatocellular carcinoma models [6-8]. Based on the above evidence, we conjectured that during the early phase of liver regeneration, the activity of tissue specific TF (HNF4 $\alpha)$ is repressed, so as to coordinate with other growth induced TFs (C/EBP, AP-1, NF- $\kappa$ B and USF1) in amplifying expression of hepatic genes (including promitogenic genes and homeostatic response genes) important for liver regeneration. Detailed functional study on PH models are needed to better clarify the biological relevance and molecular mechanisms of HNF4 $\alpha$ during liver regeneration priming. 


\begin{tabular}{|c|c|c|}
\hline \multirow{2}{*}{$\begin{array}{c}\text { Cellular Physiology } \\
\text { and Biochemistry }\end{array}$} & \multicolumn{2}{|c|}{ Cell Physiol Biochem 2015;36:2317-2326 } \\
\hline & $\begin{array}{l}\text { DOI: } 10.1159 / 000430195 \\
\text { Published online: July } 27,2015\end{array}$ & $\begin{array}{l}\text { (c) } 2015 \text { S. Karger AG, Basel } \\
\text { www.karger.com/cpb }\end{array}$ \\
\hline
\end{tabular}

\section{Abbreviations}

PH (partial hepatectomy); SH (sham operation); TFs (transcription factors); MOUSE OATFA (mouse oligonucleotide array-based transcription factor assay); HNF4 (hepatocyte nuclear factor 4); TFBS (TF binding site); ChIP-on-chip (chromatin immunoprecipitation followed by microarray analysis); NF- $\kappa$ B (Nuclear factor- $\kappa \mathrm{B}$ ); STAT3 (signal transducers and transcription activators 3); AP-1 (activator protein-1); C/EBP $\beta$ (CCAAT/enhancer-binding proteins $\beta$ ); USF1 (upstream stimulatory transcription factor 1 ).

\section{Acknowledgments}

This work was financially supported by the National Science Foundation of China [No. 31371362 and No. 81400654].

\section{Disclosure Statement}

The authors declare no competing financial interests.

\section{References}

1 Fausto N, Campbell JS, Riehle KJ: Liver regeneration. Hepatology 2006;43:S45-53.

2 Koniaris LG, McKillop IH, Schwartz SI, Zimmers TA: Liver regeneration. J Am Coll Surg 2003;197:634-659.

3 Bi Y, He Y, Huang J, Su Y, Zhu GH, Wang Y, Qiao M, Zhang BQ, Zhang H, Wang Z, Liu W, Cui J, Kang Q, Zhang Z, Deng Y, Li R, Zhang Q, Yang K, Luu HH, Haydon RC, He TC, Tang N. Functional characteristics of reversibly immortalized hepatic progenitor cells derived from mouse embryonic liver. Cell Physiol Biochem 2014;34:1318-1338.

4 Fausto N, Riehle KJ: Mechanisms of liver regeneration and their clinical implications. J Hepatobiliary Pancreat Surg 2005;12:181-189.

5 Walesky C, Gunewardena S, Terwilliger EF, Edwards G, Borude P, Apte U: Hepatocyte-specific deletion of hepatocyte nuclear factor-4alpha in adult mice results in increased hepatocyte proliferation. Am J Physiol Gastrointest Liver Physiol 2013;304:G26-37.

6 Walesky C, Edwards G, Borude P, Gunewardena S, O'Neil M, Yoo B, Apte U: Hepatocyte nuclear factor 4 alpha deletion promotes diethylnitrosamine-induced hepatocellular carcinoma in rodents. Hepatology 2013;57:2480-2490.

$7 \quad$ Yin C, Wang PQ Xu WP, Yang Y, Zhang Q Ning BF, Zhang PP, Zhou WP, Xie WF, Chen WS, Zhang X: Hepatocyte nuclear factor-4alpha reverses malignancy of hepatocellular carcinoma through regulating miR-134 in the DLK1-DIO3 region. Hepatology 2013;58:1964-1976.

8 White P, Brestelli JE, Kaestner KH, Greenbaum LE: Identification of transcriptional networks during liver regeneration. J Biol Chem 2005;280:3715-3722.

9 Sun YM, Zhang Y, Zeng LQ, Wu JP, Wei L, Ren AH, Shao W, Qiao JY, Zhao YC, Zhang L, Mitchelson KR, Cheng J: Broad profiling of DNA-binding transcription factor activities improves regulatory network construction in adult mouse tissues. J Proteome Res 2008; :4455-4464.

10 Lekstrom-Himes J, Xanthopoulos KG: Biological role of the CCAAT/enhancer-binding protein family of transcription factors. J Biol Chem 1998;273:28545-28548.

11 Greenbaum LE, Li W, Cressman DE, Peng Y, Ciliberto G, Poli V, Taub R: CCAAT enhancer- binding protein beta is required for normal hepatocyte proliferation in mice after partial hepatectomy. J Clin Invest 1998;102:996-1007.

12 Bundy LM, Sealy L: CCAAT/enhancer binding protein beta (C/EBPbeta)-2 transforms normal mammary epithelial cells and induces epithelial to mesenchymal transition in culture. Oncogen 2003;22:869-883.

13 Stepniak E, Ricci R, Eferl R, Sumara G, Sumara I, Rath M, Hui L, Wagner EF: c-Jun/AP-1 controls liver regeneration by repressing p53/p21 and p38 MAPK activity. Genes Dev 2006;20:2306-2314. 


\section{Cellular Physiology Cell Physiol Biochem 2015;36:2317-2326

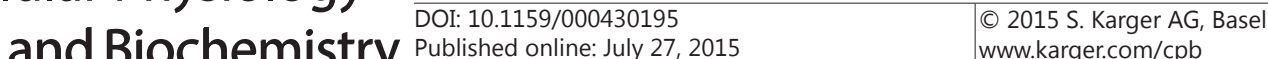 \\ Jiao/Zhu/Lu/Zheng/Chen: HNF4a-Centered Transcriptional Network During Liver Regeneration}

14 Su AI, Guidotti LG, Pezacki JP, Chisari FV, Schultz PG: Gene expression during the priming phase of liver regeneration after partial hepatectomy in mice. Proc Natl Acad Sci USA 2002;99:11181-11186.

15 Iimuro Y, Fujimoto J: TLRs, NF-kappaB, JNK, and Liver Regeneration. Gastroenterol Res Pract. DOI: $10.1155 / 2010 / 598109$.

16 Chen H, Lu S, Zhou J, Bai Z, Fu H, Xu X, Yang S, Jiao B, Sun Y: An integrated approach for the identification of USF1-centered transcriptional regulatory networks during liver regeneration. Biochim Biophys Acta 2014;1839: 415-423.

17 Kwon YS, Garcia-Bassets I, Hutt KR, Cheng CS, Jin M, Liu D, Benner C, Wang D, Ye Z, Bibikova M, Fan JB, Glass CK, Rosenfeld MG, Fu XD: Sensitive ChIP-DSL technology reveals an extensive estrogen receptor alphabinding program on human gene promoters. Proc Natl Acad Sci USA 2007;104:4852-4857.

18 Gao B, Jiang L, Kunos G: Transcriptional regulation of alpha(1b) adrenergic receptors (alpha(1b)AR) by nuclear factor 1 (NF1): a decline in the concentration of NF1 correlates with the downregulation of alpha(1b)AR gene expression in regenerating liver. Mol Cell Biol 1996;16:5997-6008.

19 Iimuro Y, Nishiura T, Hellerbrand C, Behrns KE, Schoonhoven R, Grisham JW, Brenner DA: NFkappaB prevents apoptosis and liver dysfunction during liver regeneration. J Clin Invest 1998;101:802-811.

20 Cressman DE, Greenbaum LE, Haber BA, Taub R: Rapid activation of post-hepatectomy factor/nuclear factor kappa B in hepatocytes, a primary response in the regenerating liver. J Biol Chem 1994;269:3042930435.

21 Cressman DE, Diamond RH, Taub R: Rapid activation of the Stat3 transcription complex in liver regeneration. Hepatology 1995;21:1443-1449.

22 Heim MH, Gamboni G, Beglinger C, Gyr K: Specific activation of AP-1 but not Stat3 in regenerating liver in mice. Eur J Clin Invest 1997;27:948-955.

23 Liu S, Wierød L, Skarpen E, Grøsvik H, Duan G, Huitfeldt HS. EGF activates autocrine TGF $\alpha$ to induce prolonged egf receptor signaling and hepatocyte proliferation. Cell Physiol Biochem. 2013;32:511-522.

24 Starkel P, Horsmans Y, Sempoux C, De Saeger C, Wary J, Lause P, Maiter D, Lambotte L: After portal branch ligation in rat, nuclear factor kappaB, interleukin-6, signal transducers and activators of transcription 3, c-fos, c-myc, and c-jun are similarly induced in the ligated and nonligated lobes. Hepatology 1999;29:14631470.

25 Juskeviciute E, Vadigepalli R, Hoek JB: Temporal and functional profile of the transcriptional regulatory network in the early regenerative response to partial hepatectomy in the rat. BMC Genomics 2008;9:527.

26 Morello D, Fitzgerald MJ, Babinet C, Fausto N: c-myc, c-fos, and c-jun regulation in the regenerating livers of normal and H-2K/c-myc transgenic mice. Mol Cell Biol 1990;10:3185-3193.

27 Hanlon M, Bundy LM, Sealy L: C/EBP beta and Elk-1 synergistically transactivate the c-fos serum response element. BMC Cell Biol 2000;1:2.

28 Tu YC, Huang DY, Shiah SG, Wang JS, Lin WW: Regulation of c-Fos gene expression by NF-kappaB: a p65 homodimer binding site in mouse embryonic fibroblasts but not human HEK293 cells. PloS One 2013;8:e84062.

29 Rangatia J, Vangala RK, Singh SM, Peer Zada AA, Elsasser A, Kohlmann A, Haferlach T, Tenen DG, Hiddemann W, Behre G: Elevated c-Jun expression in acute myeloid leukemias inhibits C/EBPalpha DNA binding via leucine zipper domain interaction. Oncogene 2003;22:4760-4764.

30 Rangatia J, Vangala RK, Treiber N, Zhang P, Radomska H, Tenen DG, Hiddemann W, Behre G: Downregulation of c-Jun expression by transcription factor C/EBPalpha is critical for granulocytic lineage commitment. Mol Cell Biol 2002;22:8681-8694. 